\title{
Svetlana Aleksiévitch, a Grande Utopia e o cotidiano: testemunhos e memórias do Homo Sovieticus
}

\author{
Svetlana Aleksiévitch, the Big Utopia and the everyday life: \\ testimonies and memories of the Homo Sovieticus \\ Svetlana Aleksiévitch, la Gran Utopía y la vida cotidiana: \\ testimonios y recuerdos del Homo Sovieticus
}

Fernando Perlatto*

\begin{abstract}
Resumo: Ao longo das últimas décadas, a historiografia brasileira tem dedicado cada vez mais atenção ao estudo da vida cotidiana, valorizando dimensões e aspectos que foram negligenciados pelas pesquisas influenciadas por abordagens estruturalistas. As pesquisas sobre os regimes autoritários no Brasil, particularmente, têm se beneficiado diretamente deste processo de renovação historiográfica, buscando analisar de forma mais complexa as relações entre Estado e sociedade civil, dedicando atenção especial aos homens e mulheres "comuns" e àqueles segmentos sociais que não participaram diretamente dos embates políticos. Em diálogo com a historiografia brasileira dedicada a essa agenda de pesquisa, o presente artigo objetiva analisar a obra da escritora bielorrussa Svetlana Aleksiévitch no sentido de refletir sobre o cotidiano de homens e mulheres "comuns" durante os anos da experiência autoritária da União Soviética. A partir da mobilização de milhares de testemunhos, os livros de Aleksiévitch, que formam o que ela chamou de "Enciclopédia Vermelha", contribuem para uma melhor compreensão da relação entre os "grandes" acontecimentos que tiveram curso na URSS impulsionados pela "Grande Utopia" socialista no século XX e o cotidiano do Homo Sovieticus.
\end{abstract}

Palavras-chave: Svetlana Aleksiévitch; Grande Utopia; cotidiano; Homo Sovieticus

\begin{abstract}
Over the past decades, Brazilian historiography has devoted increasingly greater attention to the study of everyday life, appreciating dimensions and aspects that have been neglected by research influenced by structuralist approaches. Research on authoritarian regimes in Brazil, particularly, have been directly benefited from this process of historiographical renovation, seeking more complex ways of analyzing the state's relationship with civil society, devoting special attention to the "ordinary" man and women and to social groups that did not directly take part in political struggles. In dialogue with the Brazilian historiography dedicated to this research agenda, this articles aims to analyze the work of Belarusian writer Svetlana Aleksiévitch in order to reflect about the everyday life of "ordinary" men and women during the years of authoritarian experience of Soviet Union. Based on thousands of testimonies, Aleksiévitch's books, forming what the author herself termed "Red Encyclopedia", contribute to a better understanding of the relationship between the "big" events that took place in USSR in the twentieth century driven by the socialist "Big Utopia" and the everyday life of Homo Sovieticus.
\end{abstract}

Keywords: Svetlana Aleksiévitch; Big Utopia; everyday life; Homo Sovieticus

Resumen: Durante las últimas décadas, la historiografía brasileña ha dedicado cada vez más atención al estudio de la vida cotidiana, valorizando dimensiones y aspectos que han sido ignorados por investigaciones influenciadas por enfoques estructuralistas. Las investigaciones sobre los regímenes autoritarios en Brasil, en particular, se han beneficiado directamente

\footnotetext{
* Professor do Departamento de História e do Programa de Pós-Graduação em História da Universidade Federal de Juiz de Fora (UFJF) e Coordenador do Laboratório de História Política e Social (LAHPS-UFJF).

dados biográficos_biographic data
} 
de este proceso de renovación historiográfica, tratando de analizar de manera más compleja las relaciones entre el Estado y la sociedad civil, con especial atención a los hombres y las mujeres "comunes" y aquellos grupos sociales que no participaron directamente de los enfrentamientos políticos. En diálogo con la historiografía brasileña dedicada a esa agenda investigativa, este artículo tiene como objetivo analizar la obra de la escritora bielorrusa Svetlana Aleksiévitch con el fin de reflexionar sobre la vida cotidiana de hombres y mujeres "comunes" durante los años de la experiencia autoritaria de la Unión Soviética. A partir de la movilización de miles de testimonios, los libros de Aleksiévitch, que forman lo que ella llamó de la "Enciclopedia Roja", contribuyen a una mejor comprensión de la relación entre los "grandes" eventos que tuvieron lugar en la URSS impulsados por la "Gran Utopía" socialista en el siglo XX y la vida cotidiana del Homo Sovieticus.

Palabras clave: Svetlana Aleksiévitch; Gran Utopía; vida cotidiana; Homo Sovieticus

"E, apesar de tudo, ele existiu, o homem soviético."

(SVETLANA ALEKSIÉVITCH, A Guerra não Tem Rosto de Mulher, p. 23)

"Escrevo, procuro nos grãozinhos, nas migalhas da história do socialismo 'doméstico'... 'interior'. A maneira como ele vivia na alma. Atrai-me sempre esse pequeno espaço - a pessoa... uma pessoa. Na verdade, é aí que tudo acontece."

(SVETLANA ALEKSIÉVITCH, O Fim do Homem Soviético, p. 10)

O período que se estende de 1970 a 1980 foi marcado por um intenso processo de transformações no campo das ciências humanas, de modo geral, e da historiografia, em particular. As mudanças que tiveram curso nesse contexto conduziram à reformulação das formas de pensar a relação entre as estruturas e as ações dos sujeitos, ou dito de outro modo, as conexões entre determinismo e liberdade individual. A despeito das diferenças dos trabalhos que emergiram nesse contexto, é possível perceber em grande parte deles a insatisfação compartilhada com os grandes modelos de explicações estruturais, associados principalmente ao marxismo, ao estruturalismo e ao funcionalismo parsoniano, que dominaram as explicações no campo das ciências humanas desde, pelo menos, os anos 1950. Tratava-se, em grande medida, de recuperar o papel do ator social, a historicidade de suas ações e das estratégias individuais, a partir da crítica à dominação das explicações holísticas e totalizantes e das grandes sínteses teóricas e explicativas propostas por estes modelos, centradas nas ideias de causalidade e determinação pelo estrutural, quer pensadas em sua dimensão econômica, quer compreendidas em sua dimensão social. Buscava-se, dessa forma, restaurar o papel dos indivíduos na constituição dos laços sociais, o que implicava na valorização das redes, das situações vividas e das estratégias singulares, de modo a conferir relevância à ação reflexiva dos sujeitos, suas intenções, vontades, desejos, motivações e sentimentos (CHARTIER, 2002).
Frente a esse quadro de crise dos modelos estruturalistas, o campo historiográfico passou a ganhar novas feições, caracterizadas pelo estilhaçamento do tempo único em uma miríade de temporalidades heterogêneas, pela pluralização do campo da análise e das fontes a serem analisadas, pelo diálogo privilegiado com novas disciplinas, sobretudo a antropologia, pela valorização das ações individuais e das microdimensões, pelo privilégio da historicidade dos fenômenos sociais, das narrativas, da hermenêutica e das dimensões discursivas (DOSSE, 2003). Quer se olhe para o amplo desenvolvimento na França, no âmbito dos Annales, da nouvelle histoire ou história cultural - a partir dos trabalhos de autores como Roger Chartier, Jacques Revel e Peter Burke -, quer se olhe para a Inglaterra e a elaboração de um refinado marxismo cultural identificado com a "história vista de baixo" - levado à frente por autores como Christopher Hill, Raymond Williams, Eric Hobsbawm e, especialmente, Edward Thompson - ou para os Estados Unidos e a conformação da sofisticada história cultural de Natalie Zamon Davis e do diálogo criativo com a antropologia interpretativa de Clifford Geertz promovido por Robert Darnton - ou ainda para a chamada história da experiência cotidiana na Alemanha, o que se viu ao longo das últimas décadas, a despeito das particularidades de cada um dos autores e movimentos mencionados, foi um campo em profunda transformação, que procurava problematizar as grandes explicações estruturalistas e conferir um 
papel mais relevante à historicidade e às ações individuais.

Conectado a esse processo de renovação do campo historiográfico no sentido de valorizar as ações individuais frente às explicações estruturais, há que se destacar um movimento importante que se deu no campo da historiografia do político - sob a influência de autores diversos como Antonio Gramsci e Michel Foucault - orientado para pensar as relações de poder em suas dimensões microfísicas, com abordagens centradas não tanto no Estado, suas instituições e estruturas, e mais preocupadas em analisar de que maneira o poder se manifesta nas relações cotidianas dos indivíduos. Essa nova forma de olhar o político teve como um de seus principais corolários a problematização da vida política como uma contraposição dicotômica e maniqueísta entre Estado e sociedade civil, como se ao primeiro fossem conferidos todos os poderes e capacidade de ação, restando à sociedade civil a passividade frente às iniciativas dos atores estatais. $\mathrm{O}$ que essa nova historiografia política tem buscado realizar é problematizar tal visão e valorizar os sujeitos e seus agrupamentos como dotados de racionalidade e possibilidade de agência, ainda que se reconhecendo os constrangimentos impostos pelas dimensões

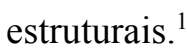

Um dos campos da historiografia que mais se beneficiou deste olhar renovado e mais complexo sobre o político, de modo geral, e acerca das relações entre Estado e sociedade civil, de modo particular, foi aquele relacionado aos estudos sobre os regimes autoritários $\mathrm{e}$ as ditaduras. $\mathrm{O}$ que as pesquisas neste campo têm buscado é relativizar a ideia de que tais regimes se mantiveram exclusivamente pela força e coerção, com um Estado se sobrepondo a uma sociedade civil passiva, que apenas reagiria à ação estatal via resistência aberta. Contra esta visão simplista, que organiza a compreensão do passado a partir de categorias como "vítima" e "algoz", "opressor" e "oprimido", a historiografia mais recente tem buscado pensar os regimes autoritários como "construções sociais", uma vez que teriam contado com o apoio implícito ou explícito de diferentes setores da sociedade, que não eram somente vítimas, mas engrenagens importantes para a manutenção desses regimes. ${ }^{2}$ Não obstante a parti-

\footnotetext{
1 Sobre a renovação da história política ver, entre outros: GOMES (1996) e RÉMOND (2003).

2 Para uma visão de diferentes pesquisas que vêm buscando compreender os regimes autoritários como "construções sociais", ver especialmente os três volumes da coletânea $A$ Construção Social dos Regimes Autoritários. Legitimidade, Consenso e Con-
}

cularidade de cada um dos regimes, os governos autoritários, seja para alcançarem o poder, seja para nele se manter, não o fizeram somente pela força e coerção, mas também pelo estabelecimento do "consenso" junto a segmentos sociais relevantes, construído a partir de diferentes iniciativas, direcionamentos e ações. ${ }^{3}$

Não se trata, é claro, de minimizar a importância dos Estados e das elites políticas no sentido de conduzirem os regimes autoritários, nem muito menos de reduzir o caráter repressivo e violento destes sistemas, mas sim de mostrar que as relações de poder eram mais complexas, plurais e heterogêneas, e que o comportamento da sociedade civil não se reduzia somente à passividade ou à resistência aberta contra o regime, sendo atravessado por ações diversas multivariadas. ${ }^{4}$ Como aponta Primo Levi (2016), em Os Afogados e os Sobreviventes, o passado, sobretudo em contextos autoritários, não pode ser compreendido a partir de explicações simplistas, mecânicas e dicotômicas, devendo antes ser olhado como uma "zona cinzenta", atravessada por comportamentos múltiplos, com contornos mal definidos, nos quais atitudes cotidianas de colaboração, aceitação, anuência, contestação abertas, escondidas ou constrangidas, se dão por meio de contradições em contextos de enorme complexidade. Esse novo olhar possibilitou compreender os contextos autoritários de forma mais plural e expandir o arco das pesquisas a

sentimento no Século $X X$, organizados por Denise Rollemberg e Samantha Quadrat (ROLLEMBERG \& QUADRAT, 2010), com destaque para os textos de Pierre Labourie (2010) sobre a ocupação nazista na França, de Didier Musiedlak (2010) sobre o fascismo italiano e de Marc Ferro (2010) sobre a União Soviética, que se constituíram como reflexões seminais para a compreensão mais complexa de contextos autoritários.

3 A noção de "consenso" sugerida por Daniel Aarão Reis é particularmente interessante no sentido de chamar a atenção para a multiplicidade de comportamentos possíveis durante a vigência de um governo autoritário: "O conceito de consenso é aqui trabalhado para compreender as relações complexas entre sociedades e regimes autoritários ou ditatoriais, no sentido da formação de um acordo de aceitação do regime existente pela sociedade, explícito ou implícito, compreendendo o apoio ativo, a simpatia acolhedora, a neutralidade benévola, a indiferença, ou no limite, a sensação de absoluta impotência. São matizes bem diferenciados e, segundo as circunstâncias, podem evoluir em direções distintas, mas concorrem todos, em dado momento, para a sustentação de um regime político ou para o enfraquecimento de uma eventual luta contra ele. A repressão e a ação da polícia política em particular podem induzir ao ou fortalecer o consenso, mas nunca devem ser compreendidas como decisivas para sua formação. O consenso, em suas diferentes gradações, se forma pelo exercício ativo da consciência, das avaliações que as pessoas e os grupos sociais fazem de suas possibilidades de ação, consideradas as expectativas e demandas no contexto político e social" (AARÃO REIS, 2010a, p. 284-5). ${ }^{4}$ As próprias resistências aos regimes autoritários têm sido encaradas a partir de novas perspectivas, problematizando-se visões simplificadoras sobre aqueles que se colocaram contra as forças da repressão. Sobre este tema ver, entre outros: ROLLEMBERG (2015). 
partir da valorização da pluralidade de comportamentos de homens e mulheres "comuns" e, especialmente, de uma nova agenda orientada para a investigação sobre o cotidiano, o prosaico e o aparentemente trivial na vigência desses regimes. ${ }^{5}$

Em diálogo com a historiografia brasileira dedicada a essa agenda de pesquisa, o presente artigo objetiva analisar a obra da escritora bielorrussa Svetlana Aleksiévitch no sentido de refletir sobre o cotidiano, em suas múltiplas manifestações e contradições, durante os anos da experiência autoritária da União Soviética. ${ }^{6}$ Autora daquilo que ela mesma denominou de "Enciclopédia Vermelha" ou "Ciclo Vermelho", composto por seis grandes obras - A Guerra não Tem Rosto de Mulher (1985); As Últimas Testemunhas. Crianças na Segunda Guerra Mundial (1985); Os Rapazes de Zinco. Vozes Soviéticas da Guerra do Afeganistão (1991); Encantados com a Morte (1993); Vozes de Tchernóbil. A História Oral do Desastre Nuclear (1997) e O Fim do Homem Soviético. Um Tempo de Desencanto (2013) -, escritas durante mais de trintas anos, Aleksiévitch, a partir de diferentes prismas, buscou refletir sobre histórias, experiências e trajetórias de homens e mulheres "comuns" soviéticos, com escritos orientados especialmente no sentido de reconstruir aquilo que denomina de "história de emoções". Os livros da autora buscam trazer à tona a dialética entre a "grande" e a "pequena" história, ou dito em outros termos, entre os acontecimentos que tiveram curso na URSS impulsionados pela "Grande Utopia" socialista e o cotidiano do Homo Sovieticus. ${ }^{7}$

\footnotetext{
5 Diferentes pesquisas que vêm buscando abordar o cotidiano vêm se beneficiando do diálogo direto com a sociologia que buscou pensar as dimensões do cotidiano, com destaque para as abordagens fenomenológicas e etnometodológica de Alfred Schutz, Herbert Blumer e Harold Garfinkel, além da "microssociologia dramatúrgica" de Erving Goffman e da sociologia cotidiana de Henri Lefebvre. Sobre o tema ver, entre outros: HELLER (2008) e MARTINS (2014).

6 Para os fins do argumento desenvolvido, no decorrer do texto, em diálogo com a bibliografia anteriormente mencionada, adotarei o termo "autoritarismo" - e não "totalitarismo" ou "totalizante" para me referir ao regime soviético, embora reconheça a pluralidade de visões no debate no campo historiográfico sobre a melhor conceituação para a compreensão da URSS. Sobre este tema ver, entre outros: ARENDT (1989); LOSURDO (2003); FERRO (2010); SEGRILLO (2010). Para uma análise sobre o cotidiano na URSS durante o stalinismo ver, entre outros: FITZPATRICK (2000).

7 Foram publicadas em português, até o presente momento, apenas três obras de Svetlana Aleksiévitch: A Guerra não Tem Rosto de Mulher (ALEKSIÉVITCH, 2016a); Vozes de Tchernóbil (ALEKSIÉVITCH, 2016b) e O Fim do Homem Soviético (ALEKSIÉVITCH, 2015). Para o presente artigo, embora tenha utilizado a tradução espanhola de Os Rapazes de Zinco (ALEKSIÉVITCH, 2016c) e as traduções alemãs de As Últimas Testemunhas (ALEKSIÉVITCH, 2005) e de Encantados com a Morte (ALEKSIÉVITCH, 1999), mantive no decorrer do texto as traduções dos títulos em português.
}

$\mathrm{O}$ artigo está dividido em três partes. Na primeira delas, buscarei construir uma reflexão mais geral sobre a abordagem de Svetlana Aleksiévitch, com o intuito de demonstrar de que maneira seus trabalhos têm buscado valorizar as experiências cotidianas plurais e diversificadas dos homens e mulheres soviéticos, em uma análise dialética refinada entre os "grandes" eventos e catástrofes do século XX nos quais a URSS esteve envolvida e aqueles acontecimentos aparentemente corriqueiros e banais das pessoas "comuns". A partir de um registro polifônico de milhares de testemunhos, os livros da autora buscam dar voz às memórias, frustrações, sonhos, aspirações, paixões e tragédias de homens e mulheres que foram testemunhas de eventos traumáticos ao longo da conturbada experiência autoritária soviética no decorrer do século XX. Na segunda e na terceira partes do artigo, procurarei explorar de forma mais sistemática algumas das reflexões contidas nos seis livros que compõem a "Enciclopédia Vermelha" ou o "Ciclo Vermelho", de modo a evidenciar de que maneira a investigação sobre o cotidiano do Homo Sovieticus empreendida por Aleksiévitch contribui para lançar novas luzes para a compressão de alguns acontecimentos centrais da experiência autoritária soviética em diferentes momentos do século XX.

\section{Svetlana Aleksiévitch, o cotidiano e o "socialismo doméstico" do Homo Sovieticus}

Em seu livro O Fim do Socialismo Soviético, Svetlana Aleksiévitch (2015, p. 12) diz ser possível dividir os soviéticos em quatro gerações - a saber, a "estalinista", a "khruschovista", a "brejnevista" e a "gorbatchovista" -, sendo a autora pertencente à última. ${ }^{8}$ Embora tenha nascido em 1948, Aleksiévitch escreveu seus trabalhos que compõem a "Enciclopédia Vermelha" já nos estertores do regime soviético, em um contexto atravessado pela crise do chamado "socialismo realmente existente". 9 Sua obra está permeada pelas transformações do tempo presente e por um olhar que busca compreender o passado tendo em vista a desintegração daquilo que chamou de

\footnotetext{
A autora se refere às diferentes lideranças que conduziram a União Soviética ao longo das últimas décadas, na condição de Secretários Gerais do Comitê Central do Partido Comunista da URSS: Josef Stalin (1924-953); Nikita Khrushchov (1953-1964); Leonid Brejnev (1964-1982); Mikhail Gorbachev (1985-1991).

9 Para uma discussão sobre a noção de "socialismo realmente existente" ver, entre outros: BAHRO (1980) e AARÃO REIS (2004).
} 
"Grande Utopia" ou "Grande Ideia", que conformou e impulsionou os homens e mulheres soviéticos, desde a Revolução Russa de 1917 e a criação da URSS, em $1922 .{ }^{10} \mathrm{O}$ que singulariza a sua obra é o esforço de dar voz às pessoas "comuns", portadoras de diferentes experiências, vivências e perspectivas, no sentido de lançar um novo olhar sobre os cotidianos diversos do Homo Sovieticus em meio às grandes transformações e aos eventos traumáticos que tiveram curso na URSS ao longo do século XX.

Em discurso intitulado "A batalha perdida", proferido em dezembro de 2015 na Academia Sueca, quando recebeu o Prêmio Nobel de Literatura daquele ano, publicado no livro Vozes de Tchernóbil, Svetlana Aleksiévitch afirmou que, diferentemente do escritor Gustave Flaubert, que se definiu como um "homempena", ela se auto definia como uma "mulher ouvido", na medida em que sempre procurou, a partir de pequenos fragmentos recolhidos de vozes humanas solitárias que narram seus sentimentos, pensamentos, tristezas, alegrias e anseios - reconstruir aquilo que chama de "a história do socialismo 'doméstico', do socialismo 'interior'", aquele socialismo que se exibia não nos discursos retóricos grandiloquentes, mas que "vivia na alma das pessoas" (ALEKSIÉVITCH, 2016b, p.370) . Como destacado na epígrafe que abre este artigo, contida em O Fim do Homem Soviético, Aleksiévitch (2015, p.10) diz que procura "nos grãozinhos, nas migalhas da história do socialismo 'doméstico'... 'interior' a maneira como ele vivia na alma".

Seus livros têm capítulos com títulos como "As vozes da rua e as conversas na cozinha" ( $O$ Fim do Homem Soviético) e "O ser humano é maior que a guerra" (A Guerra Não Tem Rosto de Mulher) que buscam destacar as dimensões humanas da história soviética que a interessam. Em O Fim do Homem Soviético, Aleksiévitch (2015) destaca que, em suas entrevistas, interroga seus testemunhos não sobre o socialismo, de modo geral, mas sobre o amor, a raiva, o ódio, o ciúme, a infância, a velhice; sobre a música, as danças, os penteados, os espaços de convívio e sociabilidade; "sobre os mil pormenores da vida". Segundo ela, esta é a única forma de fazer com que o cotidiano, o habitual, o aparentemente banal apareçam na história e ganhem a dimensão e a grandeza necessárias, inclusive para um entendimento mais amplo e complexo sobre a "grande história". Na ânsia de dar voz a essas vozes silenciadas, Aleksiévitch diz

${ }^{10}$ Para uma discussão sobre a "Grande Utopia" na URSS ver, entre outros: FERREIRA (1998). que procura olhar o mundo menos com os olhos de uma historiadora e mais com os de uma humanista, o que lhe permite não apenas compreender, mas se espantar constantemente com a riqueza e "a interminável quantidade das verdades humanas" (ALEKSIÉVITCH, 2015, p. 13).

O que a atrai, em grande medida, é "esse pequeno espaço - a pessoa", uma vez que é lá "que tudo acontece" (ALEKSIÉVITCH, 2016b, p. 373). Em Os Rapazes de Zinco, Aleksiévitch destaca que ao contrário dos "grandes acontecimentos", que "permanecem fixados na História", os pequenos, aqueles cotidianos e aparentemente comezinhos, que são importantes para o "homem pequeno, desaparecem sem deixar rastros" (ALEKSIÉVITCH, 2016c, p. 22). São silenciados, pois parecem não importar para a grande narrativa. Como ressaltado nos diferentes trabalhos da autora, a ela não interessa "os grandes feitos e o heroísmo, mas aquilo que é pequeno e humano"; o que se busca no "ciclo vermelho" é a humanização da história soviética, com o objetivo de pensar de que maneira homens e mulheres comuns experenciaram concretamente, com seus sentimentos, desejos, decepções e sonhos, as "grandes" mudanças do século XX. ${ }^{11}$

É possível discutir se a "Enciclopédia Vermelha" de Aleksiévitch deve ou não ser considerada pertencente ao campo acadêmico da História, uma vez que sua trajetória foi construída nas áreas do jornalismo e da literatura. No discurso de premiação do Nobel, "A batalha perdida", anteriormente mencionado, Aleksiévitch (2016b) diz não gostar de ser identificada como jornalista, afirmando que o que pratica é literatura. Pergunta, inclusive, de forma provocativa, "o que é literatura hoje?", respondendo prontamente que na época em que vivemos, onde tudo rapidamente se "quebra e modifica", "o conteúdo rompe a forma" e "não há fronteiras entre o fato e a ficção, um transborda sobre o outro" (ALEKSIÉVITCH, 2016b, 373). Sobretudo em situações de trauma como aqueles por ela

\footnotetext{
${ }^{11}$ No livro A Guerra Não Tem Rosto de Mulher, Aleksiévitch destaca a importância que a leitura de autores como Aliés Adamóvitch e Dostoievski teve para a conformação do gênero de escrita por ela escolhido e pelo privilégio conferido à dimensão humana da história: "Uma vez veio parar em minhas mãos o livro Eu venho de uma vila em chamas, de Aliés Adamóvitch, Iánka Bril e Vladímir Koliésnik. Só tinha sentido essa estupefação uma vez, ao ler Dostoievski. Tinha uma forma incomum: um romance constituído a partir de vozes da própria vida, do que eu escutara na infância, do que agora se escuta na rua, em casa, no café, no trólebus. É isso! O círculo se fechou. Achei o que eu estava procurando. O que estava pressentindo. Aliés Adamóvitch tornouse meu professor" (ALEKSIÉVITCH, 2016b, p. 11); "Fazer a pergunta de Dostoievski: o quanto há de humano no ser humano, e como proteger esse humano em si?" (idem, p. 16-7).
} 
narrados, o que se exige é uma "superliteratura", isto é, "uma literatura que esteja além da literatura" (idem).

A discussão sobre a que gênero pertence a obra de Aleksiévitch, contudo, parece não ter grande relevância para os objetivos deste artigo, especialmente quando se considera a importância de trabalhos que não se situam especificamente no campo acadêmico stricto sensu mas que se revelam capazes de abrir novos caminhos e perspectivas para a compreensão de aspectos diferenciados do passado. Obras literárias ou fotografias, por exemplo, têm sido mobilizadas para a compreensão do passado do próprio socialismo soviético, como exemplificam trabalhos recentes de Daniel Aarão Reis (2010a; 2010b). Livros como $O$ Arquipélago Gulag, de Alexander Soljenítsin (1973), e Contos de Kolimá, de Varlan Chalámov (2015), ainda que escritos a partir de diferentes registros e linguagens, abrem possibilidades várias para a compreensão de aspectos diversos dos campos de concentração soviéticos, não devendo, portanto, haver a priori restrições para a mobilização de obras literárias para um entendimento mais amplo do passado, ainda que o pesquisador deva estar atento às questões metodológicas que isso implica. ${ }^{12}$

As obras que compõem o "Ciclo Vermelho" de Svetlana Aleksiévitch são todas ancoradas em testemunhos diretos de milhares de homens e mulheres soviéticos que experenciaram a partir de diferentes lugares, situações e contextos de grandes transformações da URSS no século XX. Há toda uma bibliografia recente que vem sendo produzida no sentido de pensar as potencialidades, mas também as complexidades, dificuldades e limites para a utilização de testemunhos diretos como fontes, sobretudo em contextos de eventos traumáticos. ${ }^{13}$ Primo Levi, por exemplo, em seu livro Os Afogados e os Sobreviventes, destaca que os testemunhos devem passar por processos de mediação e crítica, na medida em que "as recordações que jazem em nós não estão inscritas na pedra; não só tendem a apagar-se com os anos, mas muitas vezes se modificam ou mesmo aumentam, incorporando elementos estranhos" (LEVI, 2016, p. 18). Especialmente aquele quem foi ferido, diz Levi, "tende a cancelar a recordação para não renovar a dor". A recordação de um trauma é difícil "porque evocá-lo dói ou, pelo menos, perturba" (idem, p. 18). Daí, o perigo analítico de não se estabelecer maiores

${ }^{12}$ Sobre a relação entre história e literatura ver, entre outros: CHALHOUB (2003) e LIMA (2006).

${ }^{13}$ Sobre este tema ver, entre outros, SELIGMANN-SILVA (2003a); SARLO (2007); FICO (2012). mediações na mobilização destas memórias, mediações estas que têm sido destacadas como fundamentais por diversos autores que têm se dedicado ao estudo dos testemunhos de pessoas que vivenciaram contextos traumáticos (SELIGMANN-SILVA, 2008).

Em alguns momentos dos livros que compõem a "Enciclopédia Vermelha", Aleksiévitch parece incorrer nestes erros metodológicos, "naturalizando" os relatos das testemunhas das catástrofes soviéticas do século $\mathrm{XX}$, como se a força dos testemunhos fosse suficiente para extrair dali a "verdade" dos acontecimentos, e sem que houvesse a necessidade de estabelecer quaisquer mediações entre os depoimentos e o leitor. Seus livros, em geral, são divididos entre uma primeira parte introdutória, mais reflexiva, e uma segunda parte na qual são organizados e disponibilizados os testemunhos dos milhares de Homo Sovieticus composta por falas diretas, brutas, sem maior lapidação. Porém, de modo geral, Aleksiévitch se mostra atenta às aporias existentes na construção de uma obra ancorada apenas em testemunhos; sabe, como ressalta em A Guerra não Tem Rosto de Mulher, que, "ao contar, as pessoas criam, 'escrevem' sua vida"; acrescentam e "reescreverem passagens" (ALEKSIÉVITCH, 2016a, p. 13). Tem consciência de que os sentimentos e a linguagem das pessoas estão sujeitos a serem reelaborados ao longo do tempo. Reconhece, em As Vozes de Tchernóbil, que "a testemunha não é parcial", uma vez que "ao narrar, o homem cria, luta com o tempo assim como o escultor com o mármore. Ele é um ator e um criador" (ALEKSIÉVITCH, 2016b, p. 373).

O reconhecimento dos limites dos testemunhos diretos em situações de catástrofe como "imitação da realidade", contudo, não deve ser mobilizado para inviabilizá-los como fontes capazes de revelar aspectos diversos das "manifestações do "real" que outros tipos de documentos não são capazes de vislumbrar ${ }^{14}$, aspectos esses que dizem respeito justamente a dinâmicas do cotidiano, relacionadas especialmente à dimensão dos sentimentos, dos afetos, das angústias, das alegrias, das emoções, de modo geral. E são estas dimensões diversas e multifacetadas do Homo Sovieticus que emergem nos seis livros que compõem a "Enciclopédia Vermelha", jogando novas luzes para a compreensão de aspectos ainda pouco conhecidos do cotidiano de homens e mulheres soviéticos em diferentes momentos traumáticos da história da URSS no decorrer do século XX.

\footnotetext{
${ }^{14}$ Sobre esta relação entre "imitação da realidade" e "manifestação do real" na literatura de testemunho ver: SELIGMANN-SILVA (2003b).
} 


\section{A Grande Utopia, as guerras e o cotidiano do Homo Sovieticus}

Um dos elementos de maior relevância que aparece nos livros que compõem a "Enciclopédia Vermelha" especialmente em três deles, A Guerra não Tem Rosto de Mulher, As Últimas Testemunhas e Os Rapazes de Zinco - e que é central para a compreensão da trajetória soviética no século $\mathrm{XX}$ diz respeito à importância que os diferentes conflitos nos quais a URSS esteve envolvida ao longo destes anos - com destaque para a Segunda Guerra Mundial (1939-1945) e a Guerra do Afeganistão (1979-1989) - tiveram para a conformação das vidas e experiências de mulheres e homens "comuns" soviéticos. Situadas em contextos diferenciados - um conflito ocorrendo na década de 1940 e o outro no final dos anos 1970 e ao longo da década de 1980 -, as duas guerras, impulsionadas, cada qual a seu modo, pelo objetivo de defender e expandir a "Grande Utopia" para outras regiões do mundo, são exemplares das mudanças pelas quais a URSS passou ao longo do século $\mathrm{XX}$.

A Segunda Guerra Mundial se consolidou como um acontecimento decisivo para a experiência socialista soviética no século XX. Sob a liderança de Stalin, a URSS ingressou no conflito em 1941, resistindo e derrotando a ocupação nazista no território soviético coordenado pelos exércitos de Hitler e seus aliados. A vitória sobre o nazi-fascismo e o papel desempenhando pelo Exército Vermelho contribuiu, por um lado, para a construção interna de um "consenso social" em torno do poder político e da figura de Stalin - que já vinha se fortalecendo gradativamente desde os anos 1920 e 1930 frente ao "grande salto modernizante" da sociedade soviética, mediante o crescimento econômico e a expansão de processos de urbanização, industrialização, sob o impulso inicial da Nova Política Econômica (NEP), que durou de 1921 a 1928, e posteriormente dos planos quinquenais (AARÃO REIS, 2010b; SEGRILLO, 2010) - e, por outro, possibilitou a projeção e a expansão externa da "Grande Utopia" para outros países do globo. Nos anos seguintes ao fim do conflito, a URSS vivenciaria um rápido crescimento econômico e se projetaria, ao lado dos Estados Unidos, como a maior potência mundial em torno do embate daquilo que ficou conhecido como "Guerra Fria” (HOBSBAWM, 1995, p. 85).

Pela importância que teve para a história da URSS, a Segunda Guerra Mundial passou a ser intitulada pelos soviéticos como a "Grande Guerra Patriótica", narrada sempre na chave da grandiloquência e da valorização dos grandes feitos heróicos. O que Svetlana Aleksiévitch busca fazer em suas obras A Guerra Não Tem Rosto de Mulher e As Últimas Testemunhas, publicadas originalmente em meados dos anos 1980, é mostrar, a partir de um ângulo diferenciado, outras perspectivas e facetas da grande guerra. Segundo ela, seus escritos não são sobre a guerra propriamente dita, "mas sobre o ser humano na guerra" (ALEKSIÉVITCH, 2016a, p. 18); não seria, portanto, uma "história de uma guerra, mas história dos sentimentos" (idem). Conforme destacado pela própria autora no texto que abre o livro A Guerra Não Tem Rosto de Mulher, intitulado "O ser humano é maior que a guerra", muitas foram as dificuldades enfrentadas para a publicação destas obras, uma vez que não apenas a censura, mas diversos setores do mundo editorial e da sociedade soviética de modo geral demonstraram enorme resistência em ouvir histórias plurais sobre o conflito que não se restringissem única e exclusivamente à exaltação do heroísmo em torno da "Grande Vitória". O que se alegava, em contrapartida, é que aquelas histórias de milhares de mulheres e crianças, soviéticos comuns, que Aleksiévitch trazia à tona não correspondiam à "guerra certa", travada em nome da "Grande Utopia".

Aleksiévitch pergunta provocativamente sobre, então, qual seria a "guerra certa" a ser contada? Aquela com "generais e o sábio generalíssimo? Sem sangue e sem piolhos?" (ALEKSIÉVITCH, 2016a, p. 25). O que emerge a partir das páginas de A Guerra Não Tem Rosto de Mulher e de As Últimas Testemunhas é a face humana da participação da URSS na Segunda Guerra Mundial, que ganha carne, concretude, rostos, sentimentos. "E aos meus olhos, a história vai 'se humanizando', ficando mais parecida com a vida comum. Surge outra interpretação", diz Aleksiévitch (2016a, p. 13) sobre o seu trabalho. Sobretudo pelo fato de escolher narrar o conflito com base em testemunhos de mulheres e crianças que vivenciaram a guerra a partir de diferentes lugares, posições e condições - no caso de A Guerra Não Tem Rosto de Mulher, os testemunhos são recolhidos de francoatiradoras, batedoras, fuzileiras, comandantes de canhão antiaéreo, partisans, médicas, enfermeiras, cozinheiras, lavadeiras, motoristas, controladoras de tráfego, telefonistas, criptógrafas, mensageiras, mães, esposas, amigas; em As Últimas Testemunhas, os relatos são colhidos daqueles que vivenciaram a experiência da guerra como crianças em idades diversas - é possível lançar um olhar mais amplo e heterogêneo acerca dos impactos que a Segunda Guerra Mundial exerceu sobre as experiências cotidianas plurais e diversificadas desses soviéticos. 
Em A Guerra Não Tem Rosto de Mulher, Aleksiévitch (2016a, p. 12) ressalta que todo o conhecimento até então produzido sobre a experiência da guerra fora moldado a partir da "voz masculina", tomando como base de sustentação os relatos feitos pelos homens. Os cotidianos das mulheres durante a "Grande Guerra Patriótica" teriam permanecido até então completamente desconhecidos. A história do conflito se conservaria prisioneira "de representações e sensações 'masculinas' da guerra" (idem). O conflito que emerge das narrativas das mulheres, contudo, ou o que ela chama de "guerra feminina", teria "suas próprias cores, cheiros, sua iluminação e seu espaço sentimental. Suas próprias palavras" (idem). O que Aleksiévitch busca demonstrar a partir dos testemunhos é que para além da violência do conflito, as dinâmicas do cotidiano permaneciam: as pessoas cantavam, se apaixonavam, usavam bobes nos cabelos. Junto aos sofrimentos das mortes, havia outros dramas que afetavam individualmente milhares de mulheres, a exemplo do choro pelo corte de suas tranças, da separação ou morte de seus maridos ou filhos; ou ainda, a angústia que as mulheres sentiam, muito maior do que os homens, preparados para isso desde cedo, em matar, em tirar a vida do outro. O mesmo se dá em As Últimas Testemunhas: os testemunhos das crianças que vivenciaram o conflito atravessados pela dor, pelo medo, pela lembrança da fome, do abandono, do isolamento, são permeados pelas lembranças da infância, dos acontecimentos cotidianos mais comezinhos que ocorreriam naquele contexto de batalha. Sem que se reduza em absolutamente nada a barbaridade da Grande Guerra, os dramas cotidianos, das pequenas guerras particulares, ganham cor, forma e destaque nas páginas de A Guerra Não Tem Rosto de Mulher e de As Últimas Testemunhas.

Mesmo após encerrado o conflito, as marcas da Segunda Guerra Mundial permanecem no cotidiano daquelas mulheres e crianças que vivenciaram aquela experiência traumática. No caso de A Guerra Não Tem Rosto de Mulher, segundo afirma Svetlana, as mulheres voltaram do conflito com um tipo de solidão "como se viessem de outro planeta ou do além", pois elas tinham "o conhecimento de algo que os outros não têm, e só é possível conquista-lo ali, perto da morte". Ainda que os papéis lá e cá não combinassem mais, como destaca Aleksiévitch (2016a), e não obstante elas recordem de suas experiências "como se não estivessem falando de si mesmas, mas de outras garotas", se espantando com elas mesmas, a vivência do conflito ainda faz parte de suas vidas comuns. "Seus filhos ainda por muito tempo brincaram de alemães - uns em casa, outros na igreja da vila". "Depois da guerra", dirá Aleksiévitch (2016a, p. 23), "era difícil ir à feira e olhar as barracas de carne vermelha... Até a chita vermelha...", pois ações aparentemente banais como essas traziam a lembrança das barbaridades que elas experenciaram durante o conflito. Em As Últimas Testemunhas o que aparece dos depoimentos são os dramas relacionados com a necessidade daquelas crianças no período pós-guerra terem que construir suas trajetórias completamente desfeitas após o término da batalha.

Junto à Segunda Guerra Mundial, outro conflito de grande proporção, fundamental para compreender a trajetória da URSS no século XX foi a Guerra do Afeganistão, que se inicia em 1979 como um último suspiro da grande potência soviética, e termina em 1989 já no contexto e desintegração da URSS. Os soviéticos ingressam no conflito no final da década de 1970 quando o fantasma da crise já se manifestava, mas não ganhara plena concretude, parecendo até então que a URSS poderia superar os norte-americanos na corrida armamentista que então se instalara; porém, saem da guerra com o império soviético combalido, destroçados física e moralmente. Da mesma forma que buscou fazer com a Segunda Guerra Mundial, Svetlana Aleksiévitch, em seu livro Os Rapazes de Zinco, publicado originalmente em 1991, procura recolher milhares de testemunhos de soviéticos que viveram o conflito no sentido de dar visibilidade à face humana da guerra travada no Afeganistão, bem como compreender as dinâmicas do cotidiano daqueles que vivenciaram este conflito. No caso deste livro, particularmente, a narrativa de Svetlana ganha mais dramaticidade e vivacidade, pois a autora vai até a zona de conflito e se vê "em meio das pessoas da guerra, dos objetos da guerra, do tempo da guerra". Dirá ela: "o cotidiano da guerra é grandioso" (ALEKSIÉVITCH, 2016c, p. 15).

Dos testemunhos reunidos pela autora em $O s$ Rapazes de Zinco, o que emerge e ganha destaque são relatos de dor, de mortes, de feridas, das dificuldades existentes no dia a dia em meio à ausência de poços, banheiros, água, comida; narrativas dos objetos cotidianos da guerra: água, cigarros, pão; relatos do cotidiano atravessado por doenças como a febre tifoide, o cólera, a malária, a hepatite, e, sobretudo, pela ameaça permanente da morte, que invade a mente, inclusive nos momentos em que os soldados não estão diretamente na zona do conflito envolvidos em batalhas. Dirá Svetlana: "Na guerra, o que salva o homem é que a consciência se distrai, se dispersa. Porque a morte ao seu redor sempre é absurda, casual. 
Carece totalmente de qualquer significado sublime" (idem, p. 16). Interessa à autora buscar os detalhes aparentemente banais em um contexto de guerra: "todos os pormenores físicos são importantes: as mudanças do sangue exposto ao sol, o homem justo antes de sua marcha" (idem, p. 15). Seu esforço é orientado no sentido de dar voz aos sentimentos que, a despeito da barbaridade, ainda se fazem presentes; especialmente o sentimento relacionado ao que significa lutar, matar e morrer em nome de um ideal, de uma "Grande Utopia".

O que é importante ressaltar é que a experiência da guerra contra um inimigo externo em nome da "Grande Utopia" moldou a sociedade soviética durante todo o século XX, permeando o cotidiano do Homo Sovieticus. $\mathrm{O}$ que se depreende dos três livros discutidos nesta seção que fazem parte da "Enciclopédia Vermelha" - A Guerra não Tem Rosto de Mulher, As Últimas Testemunhas e Os Rapazes de Zinco - é que homens, mulheres e crianças soviéticas estavam o tempo todo em guerra ou se preparando para ela, ou, pelo menos, relembrando como eram os combates. O mundo da guerra era o único familiar e "as pessoas da guerra eram as únicas que conhecíamos" (ALEKSIÉVITCH, 2016a, p10): "nunca tínhamos vivido de outra forma, talvez nem saibamos como fazer isso". A guerra era lembrada e relembrada a todos os momentos, "na escola e em casa, nos casamentos e batizados, nos feriados e velórios. Até nas conversas das crianças" (Idem, p.9). Ainda que no contexto da Guerra Fria não tenham ocorrido conflitos abertos entre URSS e os Estados Unidos - os momentos de maior tensão ocorreram na Crise dos Mísseis em Cuba (1953), na Guerra da Coreia (1950 e 1953), no Vietnã (1955 e 1975) e no próprio Afeganistão -, a iminência do enfrentamento direto e os movimentos bélicos dos soviéticos na própria circunscrição dos seus domínios concretizados pelo Pacto de Varsóvia - a exemplo da invasão da Hungria em 1956 e da Tchecoslováquia em 1968 para a combater a "Primavera de Praga" e as tentativas de reformas liberalizantes conduzidas por Alexander Dubcek - faziam com que as preocupações inerentes à guerra atravessassem as experiências cotidianas do Homo Sovieticus. ${ }^{15}$

\footnotetext{
${ }^{15}$ A própria experiência da família da autora é permeada por experiências relacionadas à guerra: "Em nossa família, meu avô ucraniano, pai de minha mãe, morreu no front, foi enterrado em algum lugar em terras húngaras; minha avó bielorrussa, mãe do meu pai, morreu de tifo entre os partisans; de seus três filhos, dois serviram no Exército e desapareceram nos primeiros meses da guerra, só um voltou. Meu pai. Onze parentes distantes, junto com os filhos, foram queimados vivos pelos alemães - uns em sua casa, outros na igreja da vila. Em todas as famílias acontecia o mesmo. Em todas" (ALEKSIÉVITCH, 2016b, p. 10).
}

Ao narrar as trajetórias, vivências e memórias de milhares de soviéticos Svetlana Aleksiévitch busca justamente dar voz a essas experiências cotidianas permeadas por diferentes conflitos que foram travados pela URSS no século XX em nome da "Grande Utopia". Como destacado pela autora em A Guerra Não Tem Nome de Mulher, após os grandes conflitos do século XX, com suas barbáries e mortes massivas, a tarefa de escrever sobre guerras modernas demanda um outro olhar, uma "outra postura ética e metafísica". Esse novo olhar deve prioritariamente reclamar um espaço para o diminuto, o pessoal, o pequeno, que valorize as experiências de um homem, uma mulher, uma criança, em suas particularidades. Estes devem ser vistos não mais "a partir da perspectiva do Estado", mas sim a partir de uma perspectiva que leve em conta de que maneira os "grandes" acontecimentos da trágica experiência soviética do século XX reverberaram nas vidas dos milhares de soviéticos "comuns".

\section{A crise, a desintegração da Grande Utopia e o cotidiano do Homo Sovieticus}

A segunda metade dos anos 1970 e a década de 1980 testemunharam o recrudescimento da crise da URSS, que culminaria com a perestroika em 1985, conduzida por Gorbatchev, e a dissolução do bloco soviético no início dos anos 1990. A despeito das particularidades, os diferentes autores que vêm se dedicando à compreensão do declínio da URSS têm buscado destacar duas questões centrais para a crise. De um lado, a partir dos anos 1980 passou a ficar evidente que a economia soviética perdera seu viço e dinamismo e as taxas de crescimento e desenvolvimento que haviam alcançado índices impressionantes nas décadas anteriores, sob os impulsos dos planos quinquenais, do complexo industrial-militar soviético e da modernização "pelo alto", passaram a declinar. As causas estariam associadas à excessiva burocratização, centralização e inflexibilidade, que mantinham uma economia com baixa capacidade de inovação e dinamização, muito distante da revolução tecnológica e organizacional que já estava ocorrendo nos Estados Unidos. Como destacado por Hobsbawm (1995, p. 248), quando os líderes soviéticos na década de 1970 "deixaram de enfrentar o difícil problema de reformar seu sistema econômico, cavaram suas próprias covas", mostrando-se incapazes de dominar as mais modernas técnicas industriais e de serviços baseadas nas tecnologias de informação. De outro lado, além da crise econômica, 
o próprio autoritarismo passava a ser cada vez mais criticado por setores mais amplos da sociedade e a retórica da defesa da "Grande Utopia" já não dava mais conta de responder aos anseios de segmentos que reivindicavam a mudança. ${ }^{16}$

Um dos marcos simbólicos principais da crise da URSS foi o desastre nuclear ocorrido, no dia 26 de abril de 1986, no prédio do quarto bloco da Central Elétrica Nuclear de Tchernóbil, situada na cidade de Prípiat, na Ucrânia, então parte da União Soviética. No livro Vozes de Tchernóbil, publicado em 1997, Aleksiévitch (2016b) busca dar voz a vários homens, mulheres, meninos e meninas, que vivenciaram, a partir de perspectivas diversas, o desastre de Tchernóbil, e que formam o que ela intitula de forma poética nos títulos dos capítulos de "Coro dos soldados", "Coro do povo" e "Coro de crianças". Não interessa à autora reconstruir a "grande história" do acidente nuclear, pois sobre esta já teriam sido "impressas milhares de páginas e filmadas centenas de milhares de metros em película" (ALEKSIÉVITCH, 2016b, p. 40). O que lhe move é o impulso de narrar o que ela chama de "história omitida", "os rastros imperceptíveis da nossa passagem pela Terra e pelo tempo" (idem). O foco do livro não é o extraordinário do desastre em si, mas sim seus impactos e consequências sobre o cotidiano de milhares de pessoas, que junto ao estouro da central nuclear assistiam à explosão de sonhos construídos em torno da "Grande Utopia".

Apesar das particularidades de cada um dos relatos que compõem o livro de Aleksiévitch, um sentimento que atravessa a quase totalidade das falas é o de que se vivia, a partir da explosão dos reatores de Tchernóbil, algo completamente novo na história; daí, a presença constante do tema do tempo, manifestado em expressões como "primeira vez", "nunca mais", "para sempre". Tchernóbil, isso é óbvio, é, sobretudo, algo novo para aqueles que vivenciaram concretamente aquela catástrofe, especialmente pelo fato de que suas respectivas identidades após aquele evento passam a estar invariável e fatalmente associadas à tragédia. Como diz com precisão em um dos relatos uma testemunha: "O mundo se dividiu: há os de Tchernóbil, nós; e há vocês, o resto dos homens (...). Todos nos chamamos pessoas de Tchernóbil. Nós somos de Tchernóbil, eu sou de Tchernóbil. É como se fossemos um povo à parte... uma nova nação" (ALEKSIÉVITCH, 2016b, p. 172). Ou o que fala outra pessoa entrevistada:

${ }^{16}$ Sobre a crise da URSS ver, entre outros: AARÃO REIS (1993) e SEGRILLO (2000). "vivemos num gulag. O gulag de Tchernóbil" (idem, p.282). Porém, a novidade de Tchernóbil transcende a experiência daqueles que vivenciaram de modo imediato e direto a explosão seguida de um incêndio na usina nuclear. A explosão dos reatores inaugura um novo mundo que se distingue principalmente pela incapacidade de compreensão, pois representa uma ameaça original à humanidade. Tchernóbil rompe "o fio do tempo".

Como bem destacado por Aleksiévitch, "o acontecimento se assemelhava a um monstro", e a partir dele, se instalou em todos "o sentimento de que havíamos alcançado o nunca visto" (idem, p. 41). O passado se faz impotente e "o arquivo onipotente (assim acreditávamos) da humanidade, não se encontrou a chave que abria a porta" (idem). É como se as próprias palavras, o vocabulário pensado para um mundo anterior à catástrofe não fosse mais capaz de expressar aquela novidade do mundo pós-Tchernóbil. Um povo como o soviético acostumado com a guerra não estava preparado para este novo tipo de conflito. As experiências da Segunda Guerra Mundial contra os alemães ou dos embates no Afeganistão a partir de 1979, trazidas à tona por muitos dos entrevistados, não dão conta de responder aos desafios colocados por esta nova realidade. O Homo Sovieticus não estava preparado "como espécie biológica" para enfrentar um inimigo incorpóreo, opaco, representado pela radiação, que não se via e que não se escutava. $\mathrm{O}$ inimigo, agora, transfigurado, não aparecia de forma concreta, mas tocava, como destaca a autora, "a relva ceifada, o peixe pescado, a caça aprisionada. As maçãs" (idem, p. 44).

O cotidiano, antes familiar, seguro e amistoso, a partir deste momento passa a inspirar o medo e o pavor. Como diz um psicólogo entrevistado por Aleksiévitch, o "mal é outro" e contra ele não se sabe bem o que fazer, não é possível compreendê-lo e não se tem quaisquer conhecimentos sobre como domá-lo, como enfrentá-lo. Pergunta a autora: "Estaria dentro da nossa capacidade alcançar e reconhecer um sentido nesse horror que ainda desconhecemos?" (idem, p. 39). Após a explosão, o silêncio; cidades fantasmas; tudo que antes lembrava vida passa a representar o vazio: "objetos sem homem, paisagem sem homem. Estradas para lugar nenhum, cabos para parte alguma. Você se pergunta o que é isso: passado ou futuro?'(idem, p. 51).

As destruições provocadas pela ciência e pela técnica são profundas, e têm impactos não somente sobre o próprio homem, mas também sobre todos os demais seres vivos. O homem salvou sua pele, diz Aleksiévitch, mas deixou de lado o restante da natureza. 
Quando ocorre o acidente na usina nuclear, animais como minhocas e abelhas começam rapidamente a agir de forma completamente diferenciada, adotando comportamentos estranhos em resposta à radiação propagada, antes mesmo que as notícias se espalhassem e aqueles homens, não diretamente envolvidos quando da explosão, ficassem sabendo do acontecimento. Isso faz com que Aleksiévitch pergunte: "Quem de nós é o primeiro, quem está mais sólida e eternamente ligado à terra, nós ou eles? Devíamos aprender com eles como sobreviver. E como viver" (idem, p. 48). E faz com que ela passe a encarar o mundo a partir de outros olhos. Em uma bela e sensível passagem, a autora diz: "Uma pequena formiga se arrasta pela terra, e ela agora me é próxima. Um pássaro voa no céu e também me é próximo. Entre mim e eles, o espaço se reduziu. Não há mais o abismo de antes. Tudo é vida" (idem).

Tchernóbil consiste precisamente na coincidência de duas catástrofes, a coletiva e a individual. De uma parte, o acidente é o último suspiro da União Soviética e de sua pesada burocracia, que poucos anos depois, sob a presidência de Gorbachev se desintegraria, marcando o fim da experiência socialista "realmente existente"; a irresponsabilidade do governo soviético, que omite informações e envia para o território do acidente nuclear milhares de soldados sem os resguardar e não presta à população que vivia na região da usina as informações necessárias sobre como se proteger, evidencia o colapso de um regime que já vinha mostrando sinais de enfraquecimento; de outra parte, a catástrofe é o último suspiro do "homem vermelho", o Homo Sovieticus, aquele que estava disposto a subsumir a sua individualidade em nome do dever e da causa comum da luta comum pela "Grande Utopia".

Um dos aspectos que aparece com destaque nos dois outros livros de Aleksiévitch que têm como tema a desintegração da URSS - a saber, Encantados com a Morte e O Fim do Homem Soviético, publicados, respectivamente, em 1993 e 2013 - se relaciona precisamente com a compreensão dos impactos cotidianos sobre o Homo Sovieticus do fim da "Grande Utopia". Em questão de poucos anos, tudo se transformou: "novas emoções, estados, reações"; "de súbito tudo em redor como que se tornou diferente: as tabuletas, as coisas, o dinheiro, a bandeira" e "até o próprio homem" se tornou "mais colorido, solto, explodiram o monólito, e a vida espalhou-se em ilhas, átomos, células" (ALEKSIÉVITCH, 2015, p. 13). As consequências desse processo são contraditórias: se de um lado, o fim da "Grande Utopia" possibilitou o fortalecimento da dimensão individual e subjetiva, que permanecera dominada, controlada, domesticada, nos anos autoritários, de outro, ela perturbou profundamente o cotidiano de homens e mulheres soviéticos, que, de uma hora para outra, se viram despidos de suas ideologias, bandeiras e sonhos coletivos. Pergunta Aleksiévitch: seria necessário aprender a viver sem uma grande ideia? Jogadas no turbilhão do individualismo do mercado e no vazio de um mundo que lhes era estranho, estas subjetividades libertadas daquilo que um dos entrevistados chama de "mentalidade soviética", se viram, a partir daquele momento, diante de uma série de dúvidas, inquietações e questionamentos profundos. De forma paradoxal, após o fim da URSS, o Homo Sovieticus nunca esteve "tão só como nos primeiros dias de liberdade".

A obra Encantados com a Morte é dedicada àqueles que encontraram no suicídio a forma de lidar com a grande crise que atingiu a URSS e com o desaparecimento da utopia que orientava as suas vidas. Após 1991, milhares de suicídios foram registrados nos países do antigo domínio soviético. A partir da mobilização de diferentes testemunhos, ouvidos em cidades da Rússia, Aleksiévitch (1999) procura trazer à luz o tema tabu do suicídio relacionando-o com as dificuldades e dilemas que se colocaram para milhares de homens e mulheres comuns que tiveram que lidar com a crise da "Grande Utopia" que dava sentido às suas vidas cotidianas e aceitar o "novo mundo", a "nova história", o "novo país". Estas pessoas se encontravam no limite da existência e da não existência e não conseguiram sair da "grande história" e se acostumar com a lógica de um "novo sistema" que as forçava a "mergulhar" nas preocupações mais comezinhas de uma sociedade de mercado, perdendo-se "na existência privada". A implosão do referencial, o lamento pela desintegração das tradições, dos símbolos, dos valores e dos ideais que conferiam significado às suas existências leva a um sentimento de perda do passado, que é vislumbrada a partir de múltiplas vivências e experiências fragmentadas.

Em seu livro seguinte, O Fim do Homem Soviético, Aleksiévitch (2015) vai ainda mais fundo na busca dos rastros cotidianos da desintegração da "Grande Utopia", dos destroços da "Civilização Soviética" e dos vestígios do próprio Homo Sovieticus. Esta obra tem como subtítulo "Um tempo de desencanto" em alusão precisamente aos impactos no cotidiano da perda da "grande ideia". Isso, dirá Aleksiévitch (2015, p. 10), "nunca aconteceu na vida russa, nem a literatura russa conhece isso". Ainda que para a geração mais nova fosse relativamente mais fácil aceitar o colapso 
do ideal comunista - uma vez que não havia vivido no tempo em que "a ideia era jovem, forte, sem a perdida magia do romantismo fatal e das esperanças utópicas" -, para os mais velhos aquela transição era de uma magnitude gigantesca (idem, p. 12). A "nostalgia do ideal" se manteve e a mudança em direção à liberdade e ao mundo do consumo que para muitos, sobretudo para a pequena burguesia e para as novas gerações, era desejada e comemorada, para milhares de outros antigos soviéticos era terrível e representava a derrota, o colapso, a tragédia. Não à toa, dirá Aleksiévitch, "muitos receberam a verdade como um inimigo. E a liberdade também". ${ }^{17}$ Um fosso geracional se abriu nos países da antiga URSS em torno do significado da ideia de liberdade: "aqueles que nasceram na URSS e os que já não nasceram na URSS têm experiências distintas. São pessoas de planetas diferentes".

É interessante perceber a partir dos dois livros de Aleksiévitch - Encantados com a Morte e O Fim do Homem Soviético - o quanto o processo a queda do "Império Vermelho" não foi linear, consensual, sem resistências e dificuldades, resultando em consequências dramáticas na vida cotidiana de milhares de pessoas. A historiografia já vem problematizando esta visão e mostrando como, ao contrário do que uma narrativa construída após o fim da Guerra Fria busca sustentar, a URSS e os ideais que a sustentaram ainda faziam sentido e mantinham um grau considerável de legitimidade para vários homens e mulheres comuns no momento da sua dissolução (SEGRILLO, 2010). Relacionado a esta questão, os testemunhos mobilizados por Aleksiévitch também mostram, em consonância com a historiografia dedicada ao tema (AARÃO REIS, 2010), a relação tensa e contraditória que o Homo Sovieticus pós-desintegração mantinha e ainda mantém com seu passado e, sobretudo, com a figura de Stalin. Apesar do reconhecimento e da revolta que emergem nos depoimentos com a ausência de liberdade, com as repressões, com os campos de concentração, com as execuções, com o clima do medo, também aparecem sentimentos de nostalgia em relação a uma época de maior igualdade e justiça na qual Stalin se destacava

\footnotetext{
${ }^{17}$ Em uma passagem sensível do livro, Aleksiévitch ilustra com clareza esses conflitos internos em relação à liberdade: "Isto aconteceu durante a Primeira Guerra da Chechénia [1994-1996]... Conheci em Moscou, numa estação de caminho de ferro, uma mulher que era das proximidades de Tambov e estava de partida para a Chechénia, com o objetivo de tirar o filho da guerra: 'Não quero que ele morra. Não quero que ele mate'. O Estado já não dominava a alma dela. Era uma pessoa livre. Eram poucas pessoas assim. A maioria era daqueles a quem a liberdade irritava" (ALEKSIÉVITCH, 2015, p. 12);
}

como símbolo principal. “Ainda não conseguem deixar de amar aquilo que amavam”, dirá Aleksiévitch (2016a, p. 25). Esses sentimentos são, naturalmente, reforçados em uma conjuntura como a do tempo presente, marcada pelo avanço das relações de mercado sobre suas vidas cotidianas e pela desintegração da "Grande Utopia".

\section{Conclusão}

A busca pela compreensão de um regime autoritário a partir de uma perspectiva mais plural e heterogênea não é um exercício de simples realização uma vez que o historiador pode ser acusado de estar a reduzir os processos de opressão que ocorriam durante a sua vigência. Porém, ainda que sem cair em um relativismo e sem tergiversar na afirmação do caráter repressivo desses regimes, cabe ao historiador construir uma interpretação mais complexa e refinada, que rompa com a visão dicotômica entre um Estado opressor e uma sociedade passiva, percebendo, como a historiografia recente vem buscando fazer, os regimes autoritários enquanto processos construídos socialmente, atravessados por comportamentos diversos de adesão, de resistência, de apoios implícitos ou explícitos, de críticas abertas ou veladas. Os comportamentos, as atitudes e ações são plurais e multifacetadas e é dentro dessa heterogeneidade que devem ser compreendidas e analisadas.

Olhar a sociedade civil de forma mais heterogênea implica também em direcionar a atenção para a forma como se estruturava o cotidiano durante os regimes autoritários, inclusive daqueles que não estavam diretamente envolvidos nas lutas políticas que conformavam os sistemas em análise. Trata-se de compreender como que, em meio aos constrangimentos estruturais, sejam eles econômico-sociais, políticos ou ideológico-culturais, as pessoas amavam, se reuniam, se divertiam, se entristeciam, em suma, viviam concretamente seus dilemas pessoais que, embora aparentemente pequenos, abrem novas possibilidades para a compreensão da "grande" história dos regimes autoritários. Sem que se perca a dimensão da violência e da coerção intrínseca a quaisquer regimes autoritários, o que se procura, em grande medida, é "humanizar" a história, dando carne, concretude e sentimentos a milhares de experiências e vivências que permaneceram silenciadas durante muitos anos e que possibilitam um entendimento mais complexo dos significados, sentidos e representações que homens e 
mulheres "comuns" construíram ao longo do tempo sobre os regimes autoritários no qual viviam.

Ao mobilizar os seis livros que compõem a "Enciclopédia Vermelha" ou o "Ciclo Vermelho" da escritora bielorrussa Svetlana Aleksiévitch procurei, em diálogo com a historiografia brasileira, sugerir de que maneira suas obras abrem possibilidades para uma compreensão mais ampla e multifacetada da experiência autoritária da URSS no decorrer do século XX ao trazer à tona milhares de testemunhos de homens e mulheres "comuns", que vivenciaram, a partir de perspectivas diversas, acontecimentos traumáticos ao longo das décadas, como a Segunda Guerra Mundial (A Guerra não Tem Rosto de Mulher, As Últimas Testemunhas), a Guerra do Afeganistão (Os Rapazes de Zinco) e a desintegração do império soviético (Encantados com a Morte, Vozes de Tchernóbil e O Fim do Homem Soviético). Os testemunhos que emergem dos livros de Aleksiévitch demonstram as tensões entre as "pequenas" histórias cotidianas do Homo Sovieticus e as mudanças que tiveram curso no império soviético impulsionadas pela "Grande Utopia".

O que as obras de Aleksiévitch buscam é "captar a vida cotidiana da alma", o que a autora mesmo chamou de "história da alma", trazendo vida àquilo que "a grande história geralmente deixa de lado, que trata com desdém", que é o "pequeno espaço" do homem (ALEKSIÉVITCH, 2016b, p. 372-373). Daí, o esforço em trazer à tona os "relatos dos sentimentos e pensamentos cotidianos", que são também narrados "com palavras cotidianas". Interessante, nesse sentido, é perceber o paradoxo envolvido nessa construção narrativa: ainda que mapeando o "ordinário", os relatos mobilizados não são produzidos por pessoas que tiveram vidas "ordinárias", mas sim por "pequenos homens" cujas circunstâncias de vida não têm absolutamente nada de comum, pois, embora vivessem, anteriormente, vidas comezinhas, tiveram suas existências transformadas como decorrência das ações empreendidas em nome da "Grande Utopia" ou quando da desintegração desta "Ideia". O "pequeno homem" se transfigura, dessa forma, nos termos da própria autora, em um "pequeno grande homem", ao contar sua pequena grande história (idem, p. 373).

Embora um dos aspectos mais potentes da "Enciclopédia Vermelha" de Aleksiévitch seja a exibição dos traumas e sofrimentos do Homo Sovieticus como decorrência das consequências do autoritarismo do regime soviético no século $\mathrm{XX}$, os testemunhos por ela reunidos mostram que nem tudo foi somente destruição, aniquilamento e dor. Ao se ler os relatos e as memórias que compõem suas obras, percebe-se que em meio ao caos, à brutal experiência da perda, dos sentimentos de medo, pânico e pavor, era possível perceber a construção de sonhos, projetos, utopias, além da conformação de relações e teias de solidariedade e fraternidade entre mulheres e homens soviéticos "comuns". Além disso, a partir dos testemunhos, o que emerge das ruínas do autoritarismo, é a existência de um sentimento de amor incondicional ao outro, que foi e ainda permanece sendo, pelo que se depreende dos escritos de Svetlana Aleksiévitch, a única tábua de salvação para o "pequeno grande homem" frente a catástrofes dos regimes autoritários dos séculos XX e XXI.

\section{Referências}

AARÃO REIS, Daniel. De Volta à Estação Finlândia. Crônica de uma Viagem ao Socialismo Perdido. Rio de Janeiro: Relume \& Dumará, 1993.

. As Revoluções Russas e o Socialismo Soviético. São Paulo: Editora da UNESP, 2004.

Glória, conciliação e dissidência: imagens de um socialismo que realmente existiu. In: AARÃO REIS, Daniel et al. (Orgs.). Tradições e Modernidades. Rio de Janeiro: Editora FGV, 2010a. p. 283-307.

Stalin, stalinismo e sociedade soviética. Literatura \& História. In: ROLLEMBERG, Denise; QUADRAT, Samantha. A Construção Social dos Regimes Autoritários. Legitimidade, Consenso e Consentimento no Século XX. Rio de Janeiro: Civilização Brasileira, 2010b. Vol. 2. p. 93-119.

ALEKSIÉVITCH, Svetlana. Seht mal, wie ihr lebt. Russische Schicksale nach dem Umbruch. Berlin: Aufbau, 1999.

. Die letzten Zeugen. Kinder im Zweiten Weltkrieg. Berlin: Aufbau, 2005.

O Fim do Homem Soviético. Um Tempo de Desencanto. Porto: Porto Editora, 2015.

A Guerra Não Tem Rosto de Mulher. São Paulo: Companhia das Letras, 2016a.

. Vozes de Tchernóbil. A História Oral do Desastre Nuclear. São Paulo: Companhia das Letras, 2016 b.

. Los Muchachos de Zinc. Voces Soviéticas de la Guerra de Afganistán. Editora Debate, 2016c.

ARENDT, Hannah. As Origens do Totalitarismo. São Paulo: Companhia das Letras, 1989.

BAHRO, Rudolf. A Alternativa. Para uma Crítica do Socialismo Real. São Paulo: Paz e Terra, 1980.

CHALÁMOV, Varlan. Contos de Kolimá. São Paulo: Editora 34, 2015.

CHALHOUB, Sidney. Machado de Assis: historiador. São Paulo: Companhia das Letras, 2003.

CHARTIER, Roger. À Beira da Falésia: a História entre certezas e inquietudes. Porto Alegre: Editora da UFRGS, 2002. 
DOSSE, François. O Império do Sentido - A Humanização das Ciências Humanas. Florianópolis: EDUSC, 2003.

FERREIRA, Jorge. URSS: Mito, utopia e história. Tempo, Rio de Janeiro, v. 3, n. 5, p. 75-103, 1998.

FERRO, Marc. Há "democracia demais" na URSS? In: ROLLEMBERG, Denise; QUADRAT, Samantha. A Construção Social dos Regimes Autoritários. Legitimidade, Consenso e Consentimento no Século XX. Rio de Janeiro: Civilização Brasileira, 2010. Vol. 2. p. 65-91.

FICO, Carlos. História do Tempo Presente, eventos traumáticos e documentos sensíveis o caso brasileiro. Varia Historia, Belo Horizonte, v. 28, n. 47, p. 43-59, jan./jun. 2012. https://doi.org/ $10.1590 /$ S0104-87752012000100003

FITZPATRICK, Sheila. Everyday Stalinism. Ordinary Life in Extraordinary Times: Soviet Russia in the 1930. New York: Oxford University Press, 2000.

GOMES, Angela de Castro. Política: história, ciência, cultura etc. Estudos Históricos, Rio de Janeiro, v. 9, n. 17, p. 59-84, 1996.

HELLER, Agnes. O Cotidiano e a História. São Paulo: Paz e Terra, 2008.

HOBSBAWM, Eric. A Era dos Extremos. O Breve Século XX. 1914-1991. São Paulo: Companhia das Letras, 1995.

LABOURIE, Pierre. 1940-1944. Os franceses do pensar-duplo. In: ROLLEMBERG, Denise; QUADRAT, Samantha. A Construção Social dos Regimes Autoritários. Legitimidade, Consenso e Consentimento no Século XX. Rio de Janeiro: Civilização Brasileira, 2010. Vol. 2. p. 31-44.

LEVI, Primo. Os Afogados e os Sobreviventes. São Paulo, Rio de Janeiro: Paz e Terra, 2016.

LIMA, Luiz Costa. História, Ficção, Literatura. São Paulo: Companhia das Letras, 2006.

LOSURDO, Domenico. Para uma crítica da categoria de totalitarismo. Crítica Marxista, São Paulo, n. 17, p. 51-79, 2003.

MARTINS, José de Souza. Uma Sociologia da Vida Cotidiana. São Paulo: Contexto, 2014.

MUSIEDLAK, Didier. O fascismo italiano. Entre o consentimento e o consenso. In: ROLLEMBERG, Denise; QUADRAT, Samantha.
A Construção Social dos Regimes Autoritários. Legitimidade, Consenso e Consentimento no Século XX. Rio de Janeiro: Civilização Brasileira, 2010. Vol. 2. p. 149-175.

RÉMOND, René. Por uma História Política. Rio de Janeiro: Editora FGV, 2003.

ROLLEMBERG, Denise. Definir o conceito de Resistência: dilemas, reflexões, possibilidades. In: ROLLEMBERG, Denise; QUADRAT, Samantha (Orgs.). História e Memória das Ditaduras do Século XX. Rio de Janeiro: Editora FGV, 2015. p. 77-95.

ROLLEMBERG, Denise; QUADRAT, Samantha. A Construção Social dos Regimes Autoritários. Legitimidade, Consenso e Consentimento no Século XX. Rio de Janeiro: Civilização Brasileira, 2010

SARLO, Beatriz. Tempo Passado. Cultura da Memória e Guinada Subjetiva. São Paulo: Companhia das Letras; Minas Gerais: UFMG, 2007.

SEGRILLO, Angelo. O Declínio da URSS: Um Estudo das Causas. Rio de Janeiro: Record, 2000.

. URSS: coerção e consenso no estilo soviético. In: ROLLEMBERG, Denise; QUADRAT, Samantha. A Construção Social dos Regimes Autoritários. Legitimidade, Consenso e Consentimento no Século XX. Rio de Janeiro: Civilização Brasileira, 2010. Vol. 2. p. 121-147.

SELIGMANN-SILVA, Márcio (Org.). História, Memória, Literatura. O Testemunho na Era das Catástrofes. Campinas, SP: Editora da UNICAMP, 2003a.

SELIGMANN-SILVA, Márcio. O testemunho: entre a ficção e o "real". In: SELIGMANN-SILVA, Márcio (Org.). História, Memória, Literatura. O Testemunho na Era das Catástrofes. Campinas, SP: Editora da UNICAMP, 2003b. p. 375-90.

. Narrar o trauma. A questão dos testemunhos de catástrofes históricas. Psicologia Clínica, Rio de Janeiro, v. 20, n. 1, p. 65-82, 2008.

SOLJENÍTSIN, Alexander. Arquipélago Gulag. São Paulo: Círculo do Livro, 1973.

Recebido: 27 de julho de 2016 Aprovado: 30 de setembro de 2016

\footnotetext{
Autor/Author:

FERNANDO PERLATTO fperlatto@yahoo.com.br

- Professor do Departamento de História e do Programa de Pós-Graduação em História da Universidade Federal de Juiz de Fora (UFJF) e Coordenador do Laboratório de História Política e Social (LAHPS UFJF). Doutor em Sociologia pelo Instituto de Estudos Sociais e Políticos (IESP-UERJ). Autor do livro A Imaginação Sociológica Brasileira (CRV, 2016). Suas pesquisas concentram-se nas seguintes áreas: história política, história do tempo presente, democracia

- Professor of the Department of History and of the Post-Graduate Program in History at the Universidade Federal de Juiz de Fora (UFJF) and Coordinator of the Laboratório de História Política e Social (LAHPS-UFJF). PhD in Sociology from the Instituto de Estudos Sociais e Políticos (IESP-UERJ). Author of $A$ Imaginação Sociológica Brasileira (CRV, 2016). His research focuses on the following areas: political history, history of the present time, democracy.
} 